\title{
BMJ Open Loop and thiazide diuretic use and risk of chronic kidney disease progression: a multicentre observational cohort study
}

\author{
Jesse K Fitzpatrick (D) , ${ }^{1}$ Jingrong Yang, ${ }^{2}$ Andrew P Ambrosy, ${ }^{1,2}$ \\ Claudia Cabrera (D) , ${ }^{3}$ Bergur V Stefansson, ${ }^{3}$ Peter J Greasley, ${ }^{3}$ Jignesh Patel, ${ }^{4}$ \\ Thida C Tan, ${ }^{2}$ Alan S Go ${ }^{2}$
}

\begin{abstract}
To cite: Fitzpatrick JK, Yang J, Ambrosy AP, et al. Loop and thiazide diuretic use and risk of chronic kidney disease progression: a multicentre observational cohort study. BMJ Open 2022;12:e048755. doi:10.1136/ bmjopen-2021-048755

- Prepublication history for this paper is available online. To view these files, please visit the journal online (http://dx.doi. org/10.1136/bmjopen-2021048755).
\end{abstract}

Received 06 January 2021 Accepted 27 December 2021

Check for updates

(c) Author(s) (or their employer(s)) 2022. Re-use permitted under CC BY-NC. No commercial re-use. See rights and permissions. Published by BMJ.

${ }^{1}$ Cardiology, Kaiser Permanente San Francisco Medical Center, San Francisco, California, USA ${ }^{2}$ Division of Research, Kaiser Permanente Northern California, Oakland, California, USA

${ }^{3}$ AstraZeneca US, Wilmington, Delaware, USA

${ }^{4}$ Nephrology, Kaiser Permanente Roseville Medical Center,

Roseville, California, USA

Correspondence to

Dr Alan S Go; alan.s.go@kp.org

\section{ABSTRACT}

Objectives To evaluate the association between diuretic use by class with chronic kidney disease (CKD) progression and onset of end-stage renal disease (ESRD). Design Retrospective cohort study.

Setting Large integrated healthcare delivery system in Northern California.

Participants Adults with an estimated glomerular filtration rate (eGFR) $15-59 \mathrm{~min} / 1.73 \mathrm{~m}^{2}$ by the CKDEpidemiology Collaboration equation with no prior diuretic use.

Main outcome measures ESRD and a renal composite outcome including eGFR $<15 \mathrm{~mL} / \mathrm{min} / 1.73 \mathrm{~m}^{2}, 50 \%$ reduction in eGFR and/or ESRD.

Results Among 47666 eligible adults with eGFR $15-59 \mathrm{~min} / 1.73 \mathrm{~m}^{2}$ and no previous receipt of loop or thiazide diuretics, mean age was 71 years, $49 \%$ were women and $26 \%$ were persons of colour. Overall, the rate (per 100 person-years) of the renal composite outcome was 1.35 (95\% Cl: 1.30 to 1.41) and 0.42 (95\% Cl: 0.39 to 0.45 ) for ESRD. Crude rates (per 100 person-years) of the composite renal outcome were higher in patients who initiated loop diuretics (12.85 (95\% Cl: 11.81 to 13.98) vs 1.06 (95\% Cl: 1.02 to 1.12)) and thiazide diuretics (2.68 (95\% Cl: 2.33 to 3.08$)$ vs 1.29 (95\% Cl: 1.24 to 1.35)) compared with those who did not. Crude rates (per 100-person years) of ESRD where higher in patients who initiated loop diuretics (4.92 (95\% Cl: 4.34 to 5.59) vs 0.30 (95\% Cl: 0.28 to 0.33$)$ ), but not in those who initiated thiazide diuretics (0.30 (95\% Cl: 0.20 to 0.46$)$ vs 0.43 (95\% Cl: 0.40 to 0.46$)$ ). However, neither initiation of diuretics or type of diuretic were significantly associated with CKD progression or ESRD after accounting for receipt of other medications and time-dependent confounders using causal inference methods.

Conclusions The use of thiazide and loop diuretics was not independently associated with an increased risk of CKD progression and/or ESRD in adults with stage 3/4 CKD.

\section{INTRODUCTION}

Chronic kidney disease (CKD) is a global public health burden with a prevalence of $11 \%$ in the $\mathrm{USA}^{1}$ and $6 \%$ in the $\mathrm{UK}^{2} \mathrm{CKD}$ is defined as a persistently reduced estimated glomerular filtration rate (eGFR) $<60 \mathrm{~mL} /$
Strengths and limitations of this study

- A large and diverse cohort of over 45000 participants was used to estimate the impact of incident loop and thiazide diuretic exposure on chronic kidney disease progression.

- By excluding patients who received a loop or thiazide-type diuretic in the preceding 4 years we were able to detect early harm and limit adherence bias.

- Treatment selection bias (eg, physicians are more likely to prescribe diuretics to patients with more severe renal impairment) was limited by accounting for baseline and time-dependent confounders using causal inference statistical methods.

- Follow-up occurred over multiple years allowing for the capture of rare events such as initiation of renal replacement therapy.

- The study was conducted among insured adults in California and the results may not be completely generalisable to uninsured persons or persons in other geographical regions.

$\min / 1.73 \mathrm{~m}^{2}$, structural kidney damage or increased albuminuria. ${ }^{3}$ Progressive loss of kidney function results in reduced sodium filtration leading to volume expansion and worsening hypertension, especially in advanced CKD. Reduction in eGFR is also associated with a graded increased risk of atherosclerotic cardiovascular disease events (eg, acute myocardial infarction and ischaemic stroke), heart failure, hospitalisation and death. ${ }^{4}$

Loop and thiazide class diuretics are an important part of guideline-directed medical therapy for patients with CKD with hypertension, oedema, metabolic acidosis and/or hyperkalaemia. ${ }^{5}$ These diuretics work through inhibition of the $\mathrm{Na}^{+}-\mathrm{K}^{+}-2 \mathrm{Cl}^{-}$ cotransporter in the thick ascending limb of the loop of Henle (ie, loop diuretics) and the $\mathrm{Na}-\mathrm{Cl}$ cotransporter in the distal convoluted tubule (ie, thiazide-type diuretics) to 
promote natriuresis and volume removal. ${ }^{6}$ Diuretics can be associated with acute elevations in serum creatinine and electrolyte derangements. ${ }^{7-9}$ Whether diuretics result in direct kidney injury versus benign haemoconcentration of serum creatinine remains controversial. In addition, it is unknown if chronic diuretic use among patients with CKD is associated with durable reductions in eGFR (ie, CKD progression) or increased risk of end-stage renal disease (ESRD). No randomised controlled trials have evaluated the effect of long-term diuretic use on CKD progression. Previous observational studies ${ }^{10-12}$ have been limited by small sample sizes and confounding by treatment selection biases (eg, physicians are more likely to prescribe diuretics to patients with more severe renal impairment).

To address these challenges, we employed causal inference statistical methods to estimate the effect of use of loop and thiazide diuretics on CKD progression. These techniques account for serial change in eGFR as a covariate and act to minimise treatment selection and other important types of bias. We applied this approach to a large and diverse population with CKD receiving care within an integrated healthcare delivery system.

\section{METHODS}

\section{Source population and analysis sample}

The source population included members of Kaiser Permanente Northern California, a large integrated healthcare delivery system with 21 hospitals and >255 outpatient clinics providing comprehensive medical care to $\sim 4.5$ million members. Its membership is highly representative of the local surrounding and statewide population with regards to age, gender, race/ethnicity and socioeconomic status. ${ }^{13}$

We initially identified all adult ( $\geq 18$ years old) members between 1 January 2008 and 31 December 2012 who had at least one outpatient, non-emergency department serum creatinine measurement within a regional health plan laboratory which was converted to eGFR using the CKD Epidemiology Collaboration Equation. ${ }^{14}$ A patient's index date was defined using the first eligible serum creatinine value during the inception period. We excluded patients with an eGFR $\geq 60 \mathrm{~mL} / \mathrm{min} / 1.72 \mathrm{~m}^{2}$ and patients who had less than 12 months of continuous health plan membership and/or pharmacy benefit before the index date, as well as those who initiated renal replacement therapy (chronic dialysis or receipt of renal transplant) before the index date. For our composite outcome, we only included patients who had an index eGFR between $15-59 \mathrm{~mL} / \mathrm{min} / 1.72 \mathrm{~m}^{2}$ and at least one additional outpatient eGFR measurement during follow-up and before initiation of renal replacement therapy, if applicable. To reduce biases due to under-ascertainment of early harm as well as adherence bias in evaluating the impact of diuretic therapy and the type of diuretic used, we employed a 'new user' design ${ }^{15}$ by excluding patients who received a loop or thiazide-type diuretic within 4

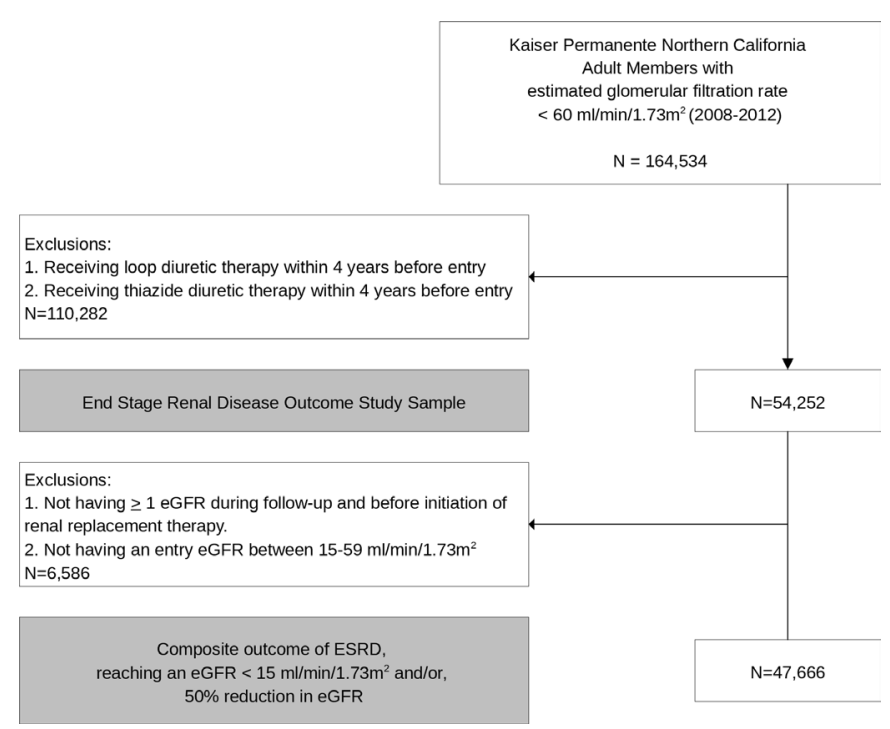

Figure 1 Assembly of analytical cohorts of eligible adults with index eGFR $<60 \mathrm{~mL} / \mathrm{min} / 1.73 \mathrm{~m}^{2}$ between 1 January 2008 and 31 December 2012 with no evidence of prior diuretic use. eGFR, estimated glomerular filtration rate; ESRD, end-stage renal disease.

years before study entry based on comprehensive health plan pharmacy dispensing data (figure 1).

\section{Patient and public involvement}

Patients and the public were not directly involved in the design, analysis, interpretation or reporting of the study findings.

\section{Diuretic exposure}

Receipt of new loop and thiazide diuretic therapy was separately identified based on dispensed prescriptions found in health plan pharmacy databases on or after index date. Longitudinal exposure was estimated from drug refill patterns according to the calculated supply (ie, in terms of days) for each prescription. For any two consecutive prescriptions, if the second prescription was filled within $\leq 14$ days of the projected end date of the first, the patient was considered to have been continually on the medication. If the second prescription was filled $>14$ days after the projected end date of the first, the patient was considered to have not been taking the medication from day 15 until the start date of the next prescription. If two prescriptions for the same drug were filled on the same day, we used the longer estimated supply to determine the end date.

\section{Follow-up and outcomes}

Follow-up began at the patient's index date and patients were censored at disenrollment, death or at the end of follow-up on 31 December 2012. Disenrollment was defined as a gap in membership of $\geq 30$ days with no evidence of interim medical care. The primary outcomes were ESRD (ie, receipt of chronic dialysis and/or kidney transplant identified from a comprehensive health plan ESRD registry) and a composite renal outcome including 
reaching an eGFR $<15 \mathrm{~mL} / \mathrm{min} / 1.73 \mathrm{~m}^{2}, 50 \%$ reduction in eGFR from baseline and/or ESRD.

\section{Covariates}

Age, sex and self-reported race/ethnicity were identified from health plan databases. We ascertained information on coexisting illnesses based on validated algorithms using data on relevant diagnoses or procedures using International Classification of Diseases, Ninth Edition and Current Procedural Terminology codes (codes available on request), laboratory results or specific therapies from health plan hospitalisation discharge, ambulatory visit, laboratory and pharmacy databases ${ }^{416}{ }^{17}$; as well as a regional diabetes mellitus registry. ${ }^{18}$ We also ascertained data on outpatient visit measures of systolic and diastolic blood pressure, body mass index, documented proteinuria based on measures of urine dipstick of $1+$ or greater, ${ }^{4}$ as well as outpatient measurements of eGFR, haemoglobin, low-density lipoprotein cholesterol, high-density lipoprotein cholesterol, serum potassium and white blood cell count. Targeted medication use was ascertained based on dispensing information from outpatient prescriptions found in health plan pharmacy databases using previously described and validated algorithms and methods. ${ }^{19-22}$

\section{Statistical analyses}

All analyses were performed using SAS software V.9.3. Baseline characteristics are presented as means with SD, medians with IQRs and frequencies with percentages. Separately for loop and thiazide diuretics, we compared patient characteristics at baseline for those who initiated or did not initiate these agents during follow-up. Given the large sample size, for continuous variables we compared characteristics between those with and without diuretic use using Cohen's D value by taking the standardised difference of means between groups and dividing by the pooled estimate, with a value $\geq 0.10$ considered significant ${ }^{23} 24$; for categorical variable, we used Cramér's V, with a value $\geq 0.10$ considered significant. ${ }^{25}{ }^{26}$ We next calculated the crude incidence of the primary composite outcome and the incidence of ESRD per 100 person-years with associated $95 \%$ CIs, overall and stratified by exposure to type of diuretic during follow-up.

For loop and thiazide diuretics separately, we applied marginal structural model (MSM) ${ }^{27}$ causal inference methods with inverse probability weighting (IPW) to estimate the effect of diuretic exposure and type on renal outcomes. The data were structured to allow the exposure to diuretics, outcome status, right-censoring status and time-dependent covariate status to be updated every 30 days during follow-up using appropriate time-ordering of these factors within each time bin. Time dependent covariates included all variables listed in table 1 except for patient demographic characteristics. Within each 30-day bin, we applied separate IPW's for type of diuretic exposure and right censoring to a weighted pooled logistic regression model where the dependent variable was only diuretic exposure. ${ }^{27}$ We used all baseline covariates as candidate variables to estimate the IPW of each type of diuretic exposure and differential censoring events (eg, death and end of study). In our models to estimate the IPW for a particular type of diuretic exposure (loop or thiazide), we also accounted for the other type of diuretic use in the model. Due to the low absolute incidence of each outcome of interest within each 30-day time bin, the resulting time discrete OR and its $95 \%$ CI were reported as the approximate relative risk of renal outcomes for exposure to specific diuretic use.

\section{RESULTS}

\section{Cohort assembly}

We identified 164534 eligible adults with at least one outpatient eGFR $<60 \mathrm{~mL} / \mathrm{min} / 1.73 \mathrm{~m}^{2}$ between 2008 and 2012 (figure 1). After exclusion for prior diuretic use, 54252 patients remained in the analytical cohort. In the analysis of the composite renal outcome, patients were further excluded if their index eGFR was $<15 \mathrm{~mL} /$ $\mathrm{min} / 1.73 \mathrm{~m}^{2}$ or if they lacked at least one additional eGFR measurement during follow-up, yielding a cohort of 47666 for the composite renal outcome. During follow-up, $11 \%$ of the cohort initiated loop diuretics and 12\% initiated thiazide diuretics.

\section{Clinical characteristics by diuretic status}

Among 47666 patients without prior diuretic exposure, mean age was $71 \pm 13$ years, $49 \%$ were women, and there was diverse representation with 9\% African-American, 12\% Asian/Pacific Islander and 9\% Hispanic. Comorbidity burden was high, with $20 \%$ having diabetes mellitus, $51 \%$ with hypertension, $60 \%$ with dyslipidaemia and $42 \%$ being current or former smokers.

Incident loop diuretic users were more likely than nonusers to be older and have a higher prevalence of medical comorbidities including atrial fibrillation/flutter, heart failure, valvular heart disease, diabetes mellitus and hypertension (table 1). Patients with incident loop diuretic use were more likely to have higher systolic pressure, lower diastolic blood pressure and be receiving beta-blockers at entry. In addition, incident loop diuretic users were more likely to have lower eGFR, haemoglobin and cholesterol levels but higher serum potassium compared with non-users.

Incident thiazide diuretic users had a similar mean age and comorbidity profile compared with non-users, though they were more likely to have elevated systolic and diastolic blood pressure (table 1).

\section{Incident diuretic use and renal outcomes}

During a median (IQR) 3.6 (1.5-4.6) years, 2302 (4.8\%) patients experienced the composite renal outcome (1.35 (95\% CI: 1.30 to 1.41$)$ per 100 person-years) and 769 (1.4\%) developed ESRD (0.42 (95\% CI: 0.39 to 0.45$)$ per 100 person-years). 
Table 1 Baseline characteristics of adults with index eGFR $15-59 \mathrm{~mL} / \mathrm{min} / 1.73 \mathrm{~m}^{2}$ between 1 January 2008 and 31 December 2012 with no prior diuretic use, overall and stratified by incident use of diuretics. Baseline characteristics shown for the composite endpoint analytical cohort, baseline characteristics of the ESRD endpoint cohort are not shown. The D value represents the standardised difference in means or proportions with a value $\geq 0.10$ being significant

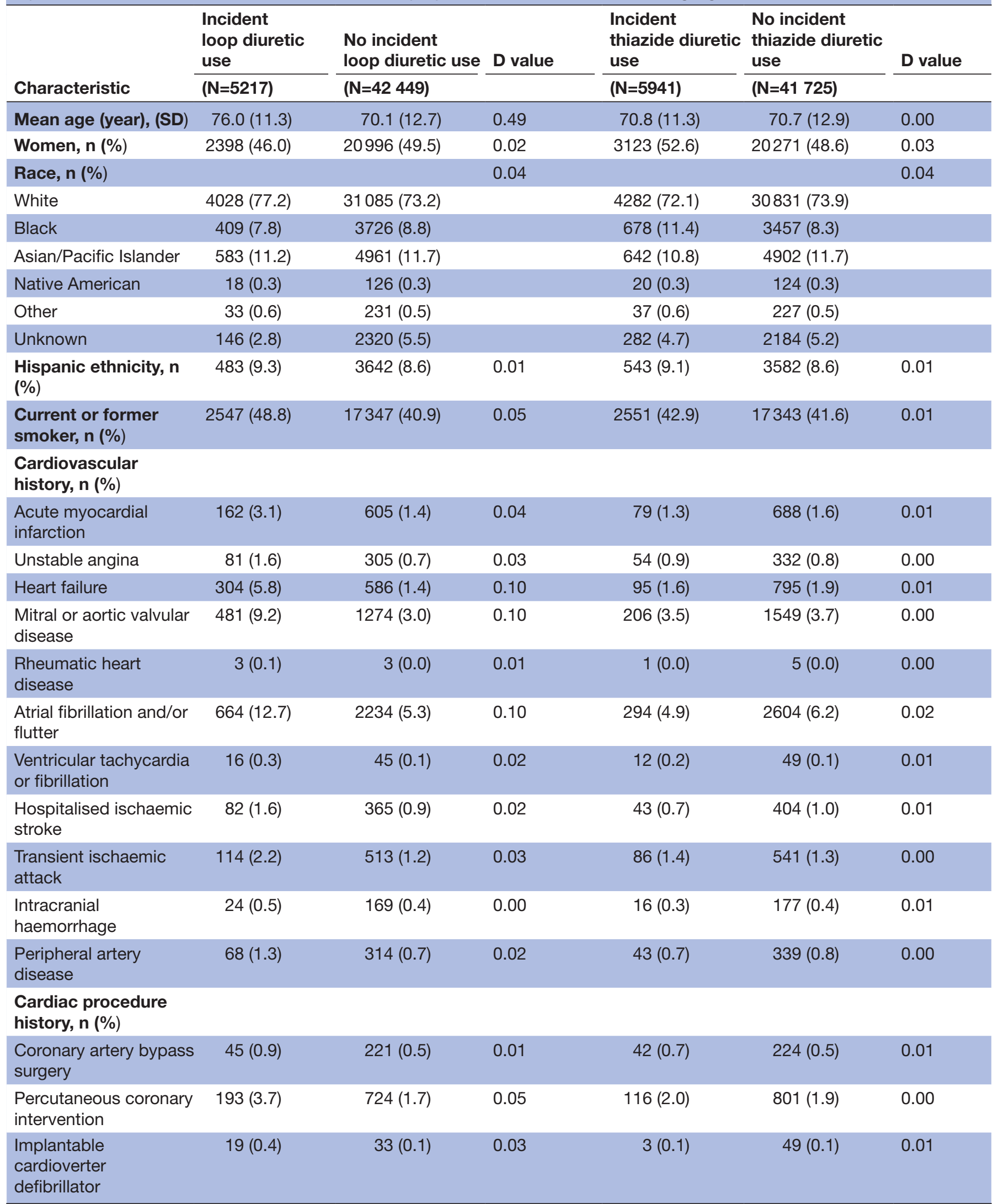


Table 1 Continued

\begin{tabular}{|c|c|c|c|c|c|c|}
\hline & $\begin{array}{l}\text { Incident } \\
\text { loop diuretic } \\
\text { use }\end{array}$ & $\begin{array}{l}\text { No incident } \\
\text { loop diuretic use }\end{array}$ & D value & $\begin{array}{l}\text { Incident } \\
\text { thiazide diuretic } \\
\text { use }\end{array}$ & $\begin{array}{l}\text { No incident } \\
\text { thiazide diuretic } \\
\text { use }\end{array}$ & D value \\
\hline Characteristic & $(\mathrm{N}=5217)$ & $(\mathrm{N}=42$ 449) & & $(\mathrm{N}=5941)$ & $(\mathrm{N}=41725)$ & \\
\hline Pacemaker & $64(1.2)$ & $163(0.4)$ & 0.04 & $22(0.4)$ & $205(0.5)$ & 0.01 \\
\hline \multicolumn{7}{|l|}{ Medical history, n (\%) } \\
\hline Diabetes mellitus & $1660(31.8)$ & 7975 (18.8) & 0.10 & $1545(26.0)$ & 8090 (19.4) & 0.05 \\
\hline Hypertension & 3639 (69.8) & $20838(49.1)$ & 0.13 & $3753(63.2)$ & $20724(49.7)$ & 0.09 \\
\hline Dyslipidaemia & 3491 (66.9) & $25025(59.0)$ & 0.05 & $3763(63.3)$ & $24753(59.3)$ & 0.03 \\
\hline Chronic liver disease & $106(2.0)$ & $619(1.5)$ & 0.01 & $98(1.6)$ & $627(1.5)$ & 0.00 \\
\hline Chronic lung disease & $1136(21.8)$ & $6676(15.7)$ & 0.05 & $1002(16.9)$ & $6810(16.3)$ & 0.00 \\
\hline Hyperthyroidism & $123(2.4)$ & $979(2.3)$ & 0.00 & $131(2.2)$ & $971(2.3)$ & 0.00 \\
\hline Hypothyroidism & $984(18.9)$ & $6800(16.0)$ & 0.02 & $980(16.5)$ & $6804(16.3)$ & 0.00 \\
\hline Systemic cancer & $383(7.3)$ & 2377 (5.6) & 0.02 & $300(5.0)$ & $2460(5.9)$ & 0.01 \\
\hline $\begin{array}{l}\text { Hospitalisation for } \\
\text { bleeding }\end{array}$ & $129(2.5)$ & $485(1.1)$ & 0.04 & 80 (1.3) & $534(1.3)$ & 0.00 \\
\hline Diagnosed dementia & $234(4.5)$ & $1633(3.8)$ & 0.01 & $117(2.0)$ & $1750(4.2)$ & 0.04 \\
\hline Diagnosed depression & $684(13.1)$ & $5511(13.0)$ & 0.00 & $694(11.7)$ & $5501(13.2)$ & 0.01 \\
\hline $\begin{array}{l}\text { Body mass index, } \mathrm{kg} / \\
\mathrm{m}^{2}, \mathrm{n}(\%)\end{array}$ & & & 0.06 & & & 0.07 \\
\hline$<18.5$ & $80(1.5)$ & $589(1.4)$ & & $61(1.0)$ & $608(1.5)$ & \\
\hline $18.5-24.9$ & $1410(27.0)$ & $12410(29.2)$ & & $1374(23.1)$ & $12446(29.8)$ & \\
\hline 25.0-29.9 & $1787(34.3)$ & $15267(36.0)$ & & $2070(34.8)$ & $14984(35.9)$ & \\
\hline 30.0-39.9 & $1341(25.7)$ & $9401(22.1)$ & & 1669 (28.1) & $9073(21.7)$ & \\
\hline$\geq 40.0$ & $213(4.1)$ & $791(1.9)$ & & $183(3.1)$ & $821(2.0)$ & \\
\hline Unknown & $386(7.4)$ & 3991 (9.4) & & $584(9.8)$ & $3793(9.1)$ & \\
\hline $\begin{array}{l}\text { Systolic blood } \\
\text { pressure (mm Hg), } \\
\text { mean (SD) }\end{array}$ & $129.8(18.2)$ & $127.5(16.3)$ & 0.13 & $135.2(18.4)$ & $126.7(16.0)$ & 0.49 \\
\hline $\begin{array}{l}\text { Diastolic blood } \\
\text { pressure }(\mathrm{mm} \mathrm{Hg}) \\
\text { mean (SD) }\end{array}$ & $70.8(10.8)$ & $72.6(10.5)$ & 0.18 & $75.2(11.6)$ & $72.0(10.4)$ & 0.29 \\
\hline \multicolumn{7}{|l|}{$\begin{array}{l}\text { Baseline medication } \\
\text { use, } \mathbf{n}(\%)\end{array}$} \\
\hline $\begin{array}{l}\text { Angiotensin-converting } \\
\text { enzyme inhibitor }\end{array}$ & 1992 (38.2) & $11520(27.1)$ & 0.08 & 2005 (33.7) & 11507 (27.6) & 0.05 \\
\hline $\begin{array}{l}\text { Angiotensin II receptor } \\
\text { blocker }\end{array}$ & $523(10.0)$ & 2624 (6.2) & 0.05 & 468 (7.9) & $2679(6.4)$ & 0.02 \\
\hline$\beta$-blocker & $2486(47.7)$ & $12666(29.8)$ & 0.12 & 2117 (35.6) & $13035(31.2)$ & 0.03 \\
\hline $\begin{array}{l}\text { Calcium channel } \\
\text { blocker }\end{array}$ & $1234(23.7)$ & 5545 (13.1) & 0.09 & 1041 (17.5) & $5738(13.8)$ & 0.04 \\
\hline $\begin{array}{l}\text { Aldosterone receptor } \\
\text { antagonist }\end{array}$ & $99(1.9)$ & $349(0.8)$ & 0.03 & $49(0.8)$ & $399(1.0)$ & 0.00 \\
\hline $\begin{array}{l}\text { Isosorbide dinitrate + } \\
\text { hydralazine }\end{array}$ & $12(0.2)$ & $13(0.0)$ & 0.03 & $4(0.1)$ & $21(0.1)$ & 0.00 \\
\hline Hydralazine & 115 (2.2) & $323(0.8)$ & 0.05 & $55(0.9)$ & $383(0.9)$ & 0.00 \\
\hline Nitrate & $378(7.2)$ & $989(2.3)$ & 0.09 & $163(2.7)$ & 1204 (2.9) & 0.00 \\
\hline Alpha blocker & 729 (14.0) & 3946 (9.3) & 0.05 & $534(9.0)$ & 4141 (9.9) & 0.01 \\
\hline Digoxin & $214(4.1)$ & $665(1.6)$ & 0.06 & $91(1.5)$ & $788(1.9)$ & 0.01 \\
\hline
\end{tabular}


Table 1 Continued

\begin{tabular}{|c|c|c|c|c|c|c|}
\hline & $\begin{array}{l}\text { Incident } \\
\text { loop diuretic } \\
\text { use }\end{array}$ & $\begin{array}{l}\text { No incident } \\
\text { loop diuretic use }\end{array}$ & D value & $\begin{array}{l}\text { Incident } \\
\text { thiazide diuretic } \\
\text { use }\end{array}$ & $\begin{array}{l}\text { No incident } \\
\text { thiazide diuretic } \\
\text { use }\end{array}$ & D value \\
\hline Characteristic & $(\mathrm{N}=5217)$ & $(\mathrm{N}=42$ 449) & & $(\mathrm{N}=5941)$ & $(\mathrm{N}=41725)$ & \\
\hline Statin & $2791(53.5)$ & $17466(41.1)$ & 0.08 & $2632(44.3)$ & $17625(42.2)$ & 0.01 \\
\hline $\begin{array}{l}\text { Other lipid-lowering } \\
\text { agent }\end{array}$ & $290(5.6)$ & $1735(4.1)$ & 0.02 & $265(4.5)$ & $1760(4.2)$ & 0.00 \\
\hline Antiarrhythmic agent & $151(2.9)$ & $460(1.1)$ & 0.05 & $72(1.2)$ & 539 (1.3) & 0.00 \\
\hline Anti-inflammatory drug & $598(11.5)$ & 5240 (12.3) & 0.01 & 799 (13.4) & 5039 (12.1) & 0.01 \\
\hline Antiplatelet agent & $391(7.5)$ & $1564(3.7)$ & 0.06 & $233(3.9)$ & $1722(4.1)$ & 0.00 \\
\hline Diabetic therapy & $1277(24.5)$ & $5853(13.8)$ & 0.09 & 1150 (19.4) & $5980(14.3)$ & 0.05 \\
\hline Aspirin & 170 (3.3) & 807 (1.9) & 0.03 & $118(2.0)$ & $859(2.1)$ & 0.00 \\
\hline Potassium & $60(1.2)$ & $265(0.6)$ & 0.02 & $39(0.7)$ & $286(0.7)$ & 0.00 \\
\hline Calcium & $7(0.1)$ & $17(0.0)$ & 0.01 & $2(0.0)$ & $22(0.1)$ & 0.00 \\
\hline Erythropoietin & $31(0.6)$ & $141(0.3)$ & 0.01 & $9(0.2)$ & $163(0.4)$ & 0.01 \\
\hline \multicolumn{7}{|l|}{$\begin{array}{l}\text { Baseline laboratory } \\
\text { values }\end{array}$} \\
\hline $\begin{array}{l}\text { Estimated GFR, } \mathrm{mL} / \\
\mathrm{min} / 1.73 \mathrm{~m}^{2}, \\
\mathrm{n}(\%)\end{array}$ & & & 0.12 & & & 0.03 \\
\hline $45-59$ & $3378(64.7)$ & $34137(80.4)$ & & $4761(80.1)$ & 32754 (78.5) & \\
\hline $0-44$ & $1470(28.2)$ & $6962(16.4)$ & & $1051(17.7)$ & $7381(17.7)$ & \\
\hline $15-29$ & $369(7.1)$ & $1350(3.2)$ & & $129(2.2)$ & $1590(3.8)$ & \\
\hline Proteinuria, $\mathrm{n}(\%)$ & $946(18.1)$ & $4286(10.1)$ & 0.08 & $716(12.1)$ & $4516(10.8)$ & 0.01 \\
\hline $\begin{array}{l}\text { Haemoglobin, g/dL, } \\
\text { n (\%) }\end{array}$ & & & 0.12 & & & 0.03 \\
\hline$\geqq 13.0$ & $2440(46.8)$ & $24982(58.9)$ & & $3327(56.0)$ & $24095(57.7)$ & \\
\hline $12.0-12.9$ & $966(18.5)$ & $5691(13.4)$ & & $829(14.0)$ & $5828(14.0)$ & \\
\hline $11.0-11.9$ & $620(11.9)$ & 2657 (6.3) & & $384(6.5)$ & 2893 (6.9) & \\
\hline $10.0-10.9$ & $281(5.4)$ & $1027(2.4)$ & & $144(2.4)$ & $1164(2.8)$ & \\
\hline $9.0-9.9$ & $89(1.7)$ & $376(0.9)$ & & $59(1.0)$ & $406(1.0)$ & \\
\hline$<9.0$ & $63(1.2)$ & $207(0.5)$ & & $21(0.4)$ & $249(0.6)$ & \\
\hline Unknown & 758 (14.5) & 7509 (17.7) & & 1177 (19.8) & 7090 (17.0) & \\
\hline $\begin{array}{l}\text { Total cholesterol (mg/ } \\
\mathrm{dL}) \text {, mean (SD) }\end{array}$ & $176.1(43.3)$ & $188.9(43.8)$ & 0.29 & $188.9(45.3)$ & $187.3(43.7)$ & 0.04 \\
\hline $\begin{array}{l}\text { Low density lipoprotein } \\
\text { cholesterol (mg/dL), } \\
\text { mean (SD) }\end{array}$ & $97.9(34.4)$ & $108.4(36.2)$ & 0.30 & $107.6(36.2)$ & $107.2(36.2)$ & 0.01 \\
\hline $\begin{array}{l}\text { High density } \\
\text { lipoprotein cholesterol } \\
\text { (mg/dL), mean (SD) }\end{array}$ & $48.9(14.7)$ & $51.1(14.8)$ & 0.15 & $50.4(14.6)$ & $50.9(14.9)$ & 0.04 \\
\hline $\begin{array}{l}\text { Serum potassium } \\
\text { (mmol/L), mean (SD) }\end{array}$ & $4.7(0.5)$ & $4.6(0.4)$ & 0.18 & $4.6(0.5)$ & $4.6(0.4)$ & 0.04 \\
\hline $\begin{array}{l}\text { White blood cell count } \\
\left(x 10^{3}\right) \text {, mean }(\mathrm{SD})\end{array}$ & $7.6(5.8)$ & $7.2(4.9)$ & 0.07 & $7.3(2.8)$ & $7.3(5.3)$ & 0.01 \\
\hline
\end{tabular}

eGFR, estimated glomerular filtration rate; ESRD, end-stage renal disease.

Patients initiating loop diuretic therapy had a higher crude rate of the composite renal outcome (12.85 (95\% CI: 11.81 to 13.98$)$ per 100 person-years) compared with those who did not receive loop diuretics (1.06 (95\% CI: 1.02 to 1.12 ) per 100 person-years) (table 2). Similarly, the rate (per 100 person-years) of ESRD was higher in 
Table 2 Crude rates of renal outcomes among eligible adults between 1 January 2008 and 31 December 2012 with no evidence of prior diuretic use, overall and stratified by incident use of diuretics

\begin{tabular}{llr}
\hline & $\begin{array}{l}\text { End-stage renal disease events per } \\
100 \text { person-years }\end{array}$ & $\begin{array}{l}\text { Composite renal outcome* } \\
\text { events per 100 person-years }\end{array}$ \\
\hline $\begin{array}{l}\text { Overall } \\
\text { Loop diuretic use }\end{array}$ & $0.42(0.39-0.45)$ & $1.35(1.30-1.41)$ \\
$\quad$ No incident use & $0.30(0.28-0.33)$ & $1.06(1.02-1.12)$ \\
$\quad$ Incident use & $4.92(4.34-5.59)$ & $12.85(11.81-13.98)$ \\
\hline Thiazide diuretic use & & $1.29(1.24-1.35)$ \\
\hline \multicolumn{1}{c}{ No incident use } & $0.43(0.40-0.46)$ & $2.68(2.33-3.08)$ \\
\hline Incident use & $0.30(0.20-0.46)$ & \\
\hline
\end{tabular}

${ }^{*}$ End-stage renal disease, eGFR $<15 \mathrm{~mL} / \mathrm{min} / 1.73 \mathrm{~m}^{2}$ and/or $\geq 50 \%$ reduction in eGFR.

eGFR, estimated glomerular filtration rate.

patients newly initiating loop diuretic therapy (4.92 (95\% CI: 4.34 to 5.59$))$ compared with those who did not $(0.30$ (95\% CI: 0.28 to 0.33$)$ ). However, in MSM models that adjusted for baseline and time-dependent confounders, incident loop diuretic use was not significantly associated with the composite renal outcome (adjusted OR (aOR) 1.38 (95\% CI: 0.94 to 2.03 )) or ESRD (aOR 0.72 (95\% CI: 0.35 to 1.48 )) (figure 2 ).

The rate of the composite renal outcome was significantly higher in patients initiating thiazide diuretics (2.68 (95\% CI: 2.33 to 3.08 ) per 100 person-years) compared with those who did not (1.29 (95\% CI: 1.24 to 1.35$)$ per 100 person-years) (table 2 ). The crude rate of ESRD was similar between those who initiated thiazide diuretics (0.30 (95\% CI: 0.20 to 0.46 ) per 100 person-years) and those who did not (0.43 (95\% CI: 0.40 to 0.46$)$ per 100 person-years). In MSM models that adjusted for baseline and time-dependent confounders, incident thiazide diuretic use was not associated with the composite renal

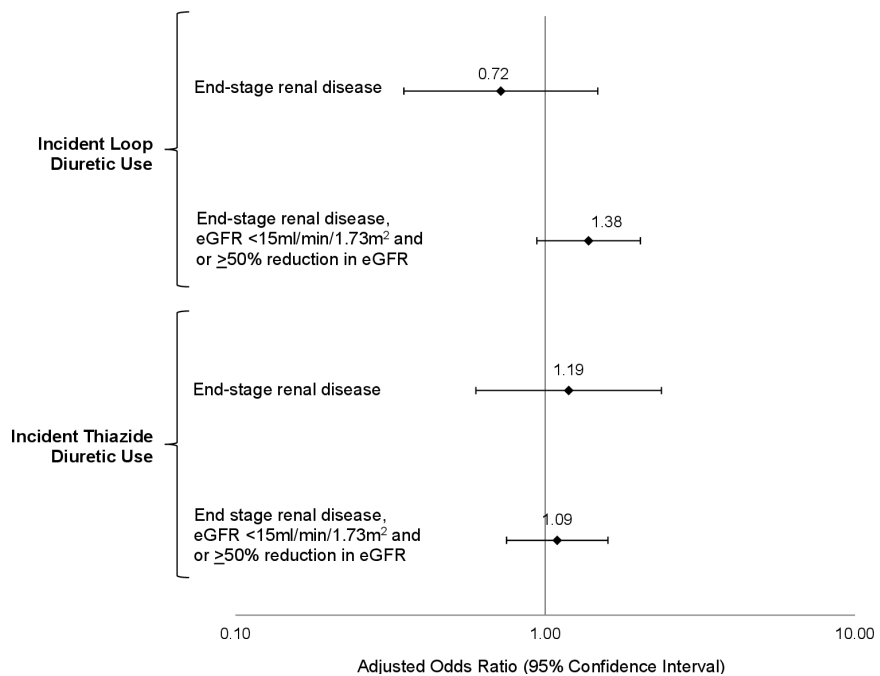

Figure 2 Marginal structural modelling estimate of incident diuretic use and outcomes in eligible adults between 1 January 2008 and 31 December 2012. eGFR, estimated glomerular filtration rate. outcome (aOR 1.09 (95\% CI: 0.75 to 1.59 )) or ESRD (aOR 1.19 (95\% CI: 0.60 to 2.37)) (figure 2).

\section{DISCUSSION}

\section{Statement of principle findings}

To our knowledge, this is the largest and most comprehensive analysis of the potential impact of incident loop and thiazide diuretic exposure on CKD progression in a real-world population with Stage 3 or Stage 4 CKD. Patients initiating loop diuretics were more than 10 times more likely to develop ESRD and the composite endpoint of CKD progression while patients initiating thiazide diuretics were twice as likely to experience the composite endpoint of CKD progression. However, after accounting for baseline characteristics and time-dependent confounders, initiation of diuretics and type of diuretic were no longer significantly associated with worse renal outcomes. Incident thiazide diuretic users were more likely to have hypertension while incident loop diuretics users were older and had more comorbidities compared with non-users. The higher rate of poor renal outcomes observed in patients prescribed diuretics was likely due to these baseline clinical differences rather than diuretic use itself. Patients with lower eGFR were also more likely to be prescribed loop diuretics which may reflect an effort to treat fluid accumulation associated with advanced CKD.

\section{Comparison with prior studies}

Although diuretics are commonly prescribed to patients with CKD, their effect on long-term renal outcomes has not been rigorously studied. Hawkins and Houston ${ }^{28}$ were the first to report on a positive correlation $(\mathrm{R}=0.754$, $\mathrm{p}=0.03$ ) between nationwide trends in thiazide prescription and rates of incident ESRD using epidemiological data from the United States Renal Data System. Several small observational studies have found associations between diuretic use and declines in eGFR in patients with pre-existing CKD. In a retrospective single-centre study of 621 patients with eGFR $15-59 \mathrm{~mL} / \mathrm{min} / 1.73 \mathrm{~m}^{2}$, diuretic use was independently associated with declines in eGFR 
(HR 2.01, $\mathrm{p}=0.01) .{ }^{11}$ In another observational cohort of 312 patients with CKD with eGFR $<60 \mathrm{~mL} / \mathrm{min} / 1.73 \mathrm{~m}^{2}$, diuretic use was associated with larger annual declines in eGFR $\left(-3.5 \pm 1.6 \mathrm{~mL} / \mathrm{min} / 1.73 \mathrm{~m}^{2}\right)$ compared with nonusers $\left(-1.6 \pm 0.77 \mathrm{~mL} / \mathrm{min} / 1.73 \mathrm{~m}^{2}\right)$ and a higher incidence of renal replacement therapy. ${ }^{29}$ Numerous small pilot studies have examined the efficacy of various loop/ thiazide diuretic combinations on blood pressure control in patients with CKD and consistently reported declines in eGFR with diuretic treatment. ${ }^{30-32}$ Larger randomised trials have compared thiazide diuretics versus nondiuretic agents in selected adults with hypertension with a low baseline prevalence of CKD. In the Antihypertensive and Lipid-Lowering Treatment to Prevent Heart Attack Trial (ALLHAT) involving 33357 participants with hypertension and cardiovascular risk factors, patient randomly assigned to chlorthalidone had lower eGFR at year 4 than those assigned to amlodipine $(\mathrm{p}<0.001)$ or lisinopril $(p=0.03)$, although there was no significant difference in incident ESRD. ${ }^{33}$ However, these previous studies all had important limitations. Observational studies have been primarily single centre, small and confounded by treatment bias. Existing randomised trials have either been very small pilots, often without non-diuretic arms, or larger hypertension treatment trials not focused on populations with CKD.

Our study materially expands on existing literature by examining a large, multicentre and diverse group of adults with CKD in a real-world, community-based setting. Follow-up occurred over multiple years starting at the initiation of the diuretic and allowed for the capture of rare events such as initiation of renal replacement therapy. Previous observational studies stratified cohorts by prevalent diuretic use at study entry which may have failed to capture early harm and introduced a treatment bias whereby patients being treated with diuretics were more likely to have severe and rapidly progressing renal disease. To address these shortcomings, we excluded patients who were on diuretics at the time of enrolment or in the preceding 4 years. We also employed serially updated MSM with IPW, allowing us to control for both baseline covariates (such as eGFR and blood pressure), changes in the status of covariates over time and timedependent confounding (ie, confounders that change over time and may be influenced by treatment or affect the likelihood of staying on treatment).

\section{Implications and future research}

Our findings appear to offer reassurance to patients with CKD receiving diuretic therapy and diverge from prior studies suggesting an excess risk of CKD progression with diuretic use. Several possible explanations may account for conflicting findings in the literature. First, diureticinduced haemoconcentration may increase serum creatinine concentration but not change in the long-term rate of eGFR decline. In this example, studies with an incomplete time horizon could erroneously interpret a drop in eGFR as evidence of long-term CKD progression. Second, failure to fully account for all relevant covariates and treatment selection bias could overestimate the association between diuretic use and reductions in eGFR. Lastly, age and comorbidity profile could mask or alter the relationship between diuretics and CKD progression. In older populations with a high comorbidity burden pathologically linked to CKD, as was evident in our cohort, even a real association between diuretics and CKD progression could be overwhelmed by the effects of comorbidities like diabetes and hypertension. For example, heart failure was fourfold more prevalent in patients prescribed loop diuretics than those who were not and could have theoretically served as an effect modifier. In patients with heart failure undergoing aggressive diuresis, elevations in serum creatinine concentration are not associated with biomarkers of tubular injury ${ }^{34}$ and have even been associated with improved survival if accompanied by evidence of decongestion. ${ }^{35}$ In cases of renal congestion caused by heart failure, diuretics may actually improve renal outcomes and could mask diuretic-induced renal injury in patients without heart failure.

Our findings highlight the need for adequately-sized randomised controlled trials with diuretic and nondiuretic arms to definitively evaluate the association between diuretic use and risk of CKD progression. Future trials must account for likely differences in blood pressure control and the presence of comorbid conditions, such as heart failure, that may alter the relationship between diuretic therapy and renal outcomes. If traditional diuretics in the loop and thiazide classes actually accelerate CKD progression, strategies to delay or avoid their use in patients with CKD will be paramount. Numerous non-diuretic anti-hypertensive agents are available and novel pharmacological agents with fluid removal mechanisms, such as vasopressin receptor antagonists (ie, aquapheresis) and sodium-glucose cotransporter 2 inhibitors (ie, glycosuria and osmosis), have shown promising safety and efficacy profiles in patients with CKD. ${ }^{36-40}$

\section{Limitations}

There are several limitations of our study. Patients were screened for enrolment based on a single laboratory creatinine corresponding to an eGFR of $<60 \mathrm{~mL} /$ $\min / 1.72 \mathrm{~m}^{2}$, risking inclusion of patients with transient elevations in serum creatinine without true CKD. We limited selection of patients with acute kidney injury by screening only ambulatory non-emergency department laboratory values. The analysis was stratified by diuretic class and we are therefore unable to comment on the risk of concurrent thiazide and loop diuretic use or detect differences between specific drugs within a class. Despite efforts to control for a wide range of baseline and timedependent confounders using causal inference methods, as an observational study of outcomes related to treatments, we cannot rule out unmeasured confounding. Lastly, because our study was conducted among insured adults in California, our results may not be completely 
generalisable to uninsured persons or persons in other geographical regions.

\section{CONCLUSIONS}

Diuretic use among patients with CKD is common, but their impact on CKD progression remains unclear. In this exploratory study, we found that incident exposure to loop or thiazide diuretics in a diverse population with CKD was not significantly associated with durable reductions in eGFR compared with non-diuretic users after accounting for baseline and time-dependent confounders. Carefully designed prospective randomised controlled trials are needed to further evaluate the impact of diuretic therapy and type on CKD progression.

Contributors Study concept and design: AG, JY and TT. Acquisition of data: AG and JY. Analysis and interpretation of data: JKF, AA, AG, JY, CC, BS, PG, JP and TT. Drafting of the manuscript: JKF, AA, AG and JY. Critical revision of the manuscript for important intellectual content: JKF, AA, AG, JY, CC, BS, PG, JP and TT. Statistical analysis: JY. Administrative, technical and material support: JY and TT. Study supervision: AG. Author responsible for the overall content as the guarantor: AG.

Funding This study was funded through a research grant to the Kaiser Permanente Northern California Division of Research from AstraZeneca (award/grant number is not applicable). The funders had no role in considering the study design or in the collection, analysis, interpretation of data, writing of the report or decision to submit the article for publication.

Competing interests CC, BS and PG are employees of and own shares in AstraZeneca which provided funding for this study through a research grant to Kaiser Permanente Northern California. There are no other financial relationships with any organisations that might have an interest in the submitted work.

Patient and public involvement Patients and/or the public were not involved in the design, or conduct, or reporting, or dissemination plans of this research.

Patient consent for publication Not applicable.

Ethics approval The study was approved by the Kaiser Permanente Northern California institutional review board, and a waiver of informed consent was obtained due to the nature of the study. The study was a retrospective analysis of previously obtained de-identified clinical data from Kaiser's EHR health system. Due to the nature of the study, informed consent was waived.

Provenance and peer review Not commissioned; externally peer reviewed.

Data availability statement Data are available upon reasonable request. Study protocol and statistical code are available from the principal investigator upon request (alan.s.go@kp.org).

Open access This is an open access article distributed in accordance with the Creative Commons Attribution Non Commercial (CC BY-NC 4.0) license, which permits others to distribute, remix, adapt, build upon this work non-commercially, and license their derivative works on different terms, provided the original work is properly cited, appropriate credit is given, any changes made indicated, and the use is non-commercial. See: http://creativecommons.org/licenses/by-nc/4.0/.

\section{ORCID iDs}

Jesse K Fitzpatrick http://orcid.org/0000-0002-1545-6399

Claudia Cabrera http://orcid.org/0000-0003-2778-1604

\section{REFERENCES}

1 Coresh J, Astor BC, Greene T, et al. Prevalence of chronic kidney disease and decreased kidney function in the adult US population: third National health and nutrition examination survey. Am J Kidney Dis 2003;41:1-12.

2 Aitken GR, Roderick PJ, Fraser S, et al. Change in prevalence of chronic kidney disease in England over time: comparison of nationally representative cross-sectional surveys from 2003 to 2010. BMJ Open 2014;4:e005480.
3 National Kidney Foundation. K/DOQI clinical practice guidelines for chronic kidney disease: evaluation, classification, and stratification. Am J Kidney Dis 2002;39:S1-266.

4 Go AS, Chertow GM, Fan D, et al. Chronic kidney disease and the risks of death, cardiovascular events, and hospitalization. $N$ Engl J Med 2004;351:1296-305.

$5 \mathrm{Ku} \mathrm{E}$, Lee BJ, Wei J, et al. Hypertension in CKD: core curriculum 2019. Am J Kidney Dis 2019;74:120-31.

6 Palmer BF. Metabolic complications associated with use of diuretics. Semin Nephrol 2011;31:542-52.

7 Wollam GL, Tarazi RC, Bravo EL, et al. Diuretic potency of combined hydrochlorothiazide and furosemide therapy in patients with azotemia. Am J Med 1982;72:929-38.

8 Trivedi H, Dresser T, Aggarwal K. Acute effect of furosemide on glomerular filtration rate in diastolic dysfunction. Ren Fail 2007;29:985-9.

9 Levi TM, Rocha MS, Almeida DN, et al. Furosemide is associated with acute kidney injury in critically ill patients. Braz J Med Biol Res 2012;45:827-33.

10 Khan YH, Sarriff A, Adnan AS, et al. Chronic kidney disease, fluid overload and diuretics: a complicated triangle. PLoS One 2016;11:e0159335.

11 Khan YH, Sarriff A, Adnan AS, et al. Progression and outcomes of non-dialysis dependent chronic kidney disease patients: a single center longitudinal follow-up study. Nephrology 2017;22:25-34.

12 Khan YH, Sarriff A, Mallhi TH, et al. Is diuretic use beneficial or harmful for patients with chronic kidney disease? Eur J Hosp Pharm 2017;24:253.2-4.

13 Gordon NP. Characteristics of adult health plan members in the Northern California region membership, as estimated from the 2011 member health survey. Oakland, CA: Division of Research, Kaiser Permanente Medical Care Program, 2013.

14 Levey AS, Stevens LA, Schmid CH. 3Rd, Feldman HI, et al. A new equation to estimate glomerular filtration rate. Ann Intern Med 2009;150:604-12.

15 Ray WA. Evaluating medication effects outside of clinical trials: newuser designs. Am J Epidemiol 2003;158:915-20.

16 Go AS, Hsu C-Y, Yang J, et al. Acute kidney injury and risk of heart failure and atherosclerotic events. Clin J Am Soc Nephrol 2018;13:833-41.

17 Go AS, Yang J, Ackerson LM, et al. Hemoglobin level, chronic kidney disease, and the risks of death and hospitalization in adults with chronic heart failure: the anemia in chronic heart failure: outcomes and resource utilization (anchor) study. Circulation 2006;113:2713-23.

18 Karter AJ, Warton EM, Lipska KJ, et al. Development and validation of a tool to identify patients with type 2 diabetes at high risk of Hypoglycemia-Related emergency department or hospital use. JAMA Intern Med 2017;177:1461-70.

19 Go AS, Lee WY, Yang J, et al. Statin therapy and risks for death and hospitalization in chronic heart failure. JAMA 2006;296:2105-11.

20 Go AS, Iribarren C, Chandra M, et al. Statin and beta-blocker therapy and the initial presentation of coronary heart disease. Ann Intern Med 2006;144:229-38.

21 Go AS, Yang J, Gurwitz JH, et al. Comparative effectiveness of betaadrenergic antagonists (atenolol, metoprolol tartrate, carvedilol) on the risk of rehospitalization in adults with heart failure. Am J Cardiol 2007;100:690-6.

22 Freeman JV, Yang J, Sung SH, et al. Effectiveness and safety of digoxin among contemporary adults with incident systolic heart failure. Circ Cardiovasc Qual Outcomes 2013;6:525-33.

23 Austin PC. Using the standardized difference to compare the prevalence of a binary variable between two groups in observational research. Commun Stat Simul Comput 2009;38:1228-34.

24 Austin PC. An introduction to propensity score methods for reducing the effects of confounding in observational studies. Multivariate Behav Res 2011;46:399-424.

25 Kotrlik J, Williams H, Jabor K. Reporting and interpreting effect size in quantitative agricultural education research. J Agric Educ 2011;52:132-42.

26 Rea LM, Parker RA. Designing and conducting survey research : a comprehensive guide. San Francisco: Jossey-Bass Publishers, 1992: 254.

27 Xie D, Yang W, Jepson C, et al. Statistical methods for modeling Time-Updated exposures in cohort studies of chronic kidney disease. Clin J Am Soc Nephrol 2017;12:1892-9.

28 Hawkins RG, Houston MC. Is population-wide diuretic use directly associated with the incidence of end-stage renal disease in the United States? A hypothesis. Am J Hypertens 2005;18:744-9. 
29 Khan YH, Sarriff A, Adnan AS, et al. Outcomes of diuretic use in pre-dialysis CKD patients with moderate renal deterioration attending tertiary care referral center. Clin Exp Nephrol 2017;21:1011-23.

30 Dussol B, Moussi-Frances J, Morange S, et al. A randomized trial of furosemide vs hydrochlorothiazide in patients with chronic renal failure and hypertension. Nephrol Dial Transplant 2005;20:349-53.

31 Dussol B, Moussi-Frances J, Morange S, et al. A pilot study comparing furosemide and hydrochlorothiazide in patients with hypertension and stage 4 or 5 chronic kidney disease. J Clin Hypertens 2012;14:32-7.

32 Cirillo M, Marcarelli F, Mele AA, et al. Parallel-Group 8-week study on chlorthalidone effects in hypertensives with low kidney function. Hypertension 2014;63:692-7.

33 Rahman M, Pressel S, Davis BR. Renal outcomes in high-risk hypertensive patients treated with an angiotensin-converting enzyme inhibitor or a calcium channel blocker vs a diuretic: a report from the antihypertensive and lipid-lowering treatment to prevent heart attack trial (ALLHAT). Arch Intern Med 2005;165:936-46.

34 Ahmad T, Jackson K, Rao VS, et al. Worsening renal function in patients with acute heart failure undergoing aggressive diuresis is not associated with tubular injury. Circulation 2018;137:2016-28.
35 Metra M, Davison B, Bettari L, et al. Is worsening renal function an ominous prognostic sign in patients with acute heart failure? the role of congestion and its interaction with renal function. Circ Heart Fail 2012;5:54-62.

36 Suzuki S, Hanafusa N, Kubota K, et al. Effects of tolvaptan on renal function in chronic kidney disease patients with volume overload. Int J Nephrol Renovasc Dis 2018;11:235-40.

37 Ikeda S, Ohshima K, Miyazaki S, et al. Impact of chronic kidney disease on the diuretic response of tolvaptan in acute decompensated heart failure. ESC Heart Fail 2017;4:614-22.

38 Nespoux J, Vallon V. Sglt2 inhibition and kidney protection. Clin Sci 2018;132:1329-39.

39 Perkovic V, Jardine MJ, Neal B, et al. Canagliflozin and renal outcomes in type 2 diabetes and nephropathy. N Engl J Med 2019;380:2295-306.

40 Heerspink HJL, Stefánsson BV, Correa-Rotter R, et al. Dapagliflozin in patients with chronic kidney disease. N Engl J Med 2020;383:1436-46. 